\title{
Cuantificación de ADN libre en plasma sanguíneo de voluntarios sanos en una población bogotana
}

\author{
Hernán David Salazar-Jordan', Dabeiba Adriana García-Robayo², \\ Jairo Amaya ${ }^{4}$, Marcos Castillo ${ }^{5,6}$, Ignacio Briceño ${ }^{6}$, Fabio Aristizábal ${ }^{3}$
}

\author{
1. Pontificia Universidad Javeriana, Departamento de Biología \\ 2. Pontificia Universidad Javeriana, Centro de Investigaciones Odontológicas \\ 3. Universidad Nacional de Colombia, Departamento de Farmacia \\ 4. Hospital de Engativá, Departamento de Ginecología \\ 5. Dinámica - IPS, Departamento de Colposcopia \\ 6. Universidad de La Sabana, Facultad de Medicina
}

Correspondencia: faaristizabalg@bt.unal.edu.co

Recibido: 14-07-09 / Aceptado: 26-09-09

\begin{abstract}
Resumen
El ADN libre en sangre incrementa con algunas condiciones patológicas y ciertos estados fisiológicos. Varios reportes en la literatura han resaltado que el ADN libre en plasma o suero tiene potencial clínico como una posible herramienta para el pronóstico de cáncer en humanos. Sin embargo, hasta el momento no se tienen valores de referencia de individuos sanos con un tamaño de muestra representativo y tampoco se han descrito valores para poblaciones específicas como la bogotana. Es por ello que en el presente estudio se cuantificó la concentración de ADN libre en personas sanas de la población bogotana y así se estableció un rango normal o valor de referencia, adicionalmente se analizó la relación entre los niveles de ADN libre y las características como edad y género. La concentración de ADN libre en la población bogotana fue de $0,72 \mathrm{ng} / \mu \mathrm{L}$ y no se encontraron diferencias significativas entre las edades y los géneros.

Palabras clave: ADN libre, ALU, PCR tiempo-real, rango de referencia.

\section{Abstract \\ Quantification of free DNA in blood plasma of healthy volunteers in Bogotá population}

The free DNA in blood increases with some pathological conditions and certain physiological state. Several reports in the literature have highlighted that the free DNA in plasma or serum has clinical potential as a possible tool for the prognosis of human cancer. However, so far there are no reference values of healthy individuals with a representative sample size and no values have been reported for specific populations such as Bogota. That is why in this study we quantified the concentration of free DNA in healthy people of the Bogota population and thus established a normal range or reference value, the relationship between levels of free DNA and characteristics such as age and gender was further analyzed. The concentration of free DNA in the Bogota population was $0.72 \mathrm{ng} / \mu \mathrm{L}$ and no significant differences between ages and genders were found.
\end{abstract}

Keywords: ALU repeats, free DNA, real-time PCR, reference value. 


\section{Introducción}

El ADN libre en sangre, bajo condiciones normales, se encuentra en muy bajas concentraciones, asociado a los procesos de muerte celular, que ocurre normalmente en el recambio celular, que a su vez se asocia entre otros al catabolismo aumentado de los glóbulos blancos en voluntarios sanos (1), lográndose cuantificar en el torrente sanguíneo en muestras como suero o plasma, además de muestras como orina, leche materna y saliva (2-4). El ADN libre es resistente a las RNAsas, debido a que éstas solo pueden degradar ADN de cadena sencilla (ssADN) mientras que el $\mathrm{ADN}$ que se encuentra libre en el torrente sanguíneo, generalmente es de doble cadena $(5,6)$.

Las concentraciones de ADN libre en sangre pueden verse alteradas por distintas circunstancias, que en general se pueden resumir en daño a tejidos, inflamación, embarazo, infecciones, cáncer y trauma (7-9). En pacientes enfermos con cáncer la concentración de $\mathrm{ADN}$ libre disminuye en respuesta a quimioterapia (10) y se incrementa cuando hay una diseminación del tumor o metástasis (10-13).

Existe gran divergencia entre valores de referencia de la concentración de ADN libre en voluntarios sanos. Para Wu y colaboradores la concentración de ADN libre en individuos sanos es de 57,1+/- 30,6 $\mathrm{ng} / \mathrm{mL}$ (14); otros muestran concentraciones de 0 hasta $35,2 \mathrm{ug} / \mathrm{mL}$ (9); para otros autores, los valores normales son de 10 a $30 \mathrm{ng} / \mathrm{mL}$ con una media de 13 $\mathrm{ng} / \mathrm{mL}$ (1) o de $18 \mathrm{ng} / \mathrm{mL}$ (15).

Adicionalmente, la concentración de este ADN aumenta en pacientes con cáncer excediendo los 100 $\mathrm{ng} / \mathrm{mL}$ hasta aproximadamente $180 \mathrm{ng} / \mathrm{mL}(1,16)$. En pacientes con cáncer de pulmón se han reportado medias de $318 \mathrm{ng} / \mathrm{mL}$ (15). Se hace necesario establecer los valores normales de la cuantificación de ADN libre en diferentes regiones de población colombiana, y así poder establecer una comparación con pacientes que padezcan alguna de las patologías anteriormente mencionadas, pues la divergencia en estos valores reportados podría llegar a ser tal que, al realizar dichas comparaciones, se incurra en errores obteniéndose valores de cuantificación equívocos que puedan resultar en un informe deficiente a la hora de hacer determinaciones de enfermedades por medio de esta técnica.

Este estudio tuvo como objetivo determinar la concentración de $\mathrm{ADN}$ libre en personas sanas en la población bogotana, para establecer un rango normal o rango de referencia mediante la técnica de PCR en Tiempo-Real sin realizar pasos de extracción y purificación de ADN.

\section{Materiales y Métodos}

\section{Recolección de muestras}

Se tomaron muestras de sangre con EDTA de 340 voluntarios sanos que asistieron a la toma de exámenes de rutina al laboratorio clínico del hospital de Engativá e IPS Dinámica. Todos los participantes firmaron el consentimiento informado.

\section{Procesamiento de las muestras}

Las muestras de sangre periférica se centrifugaron a 2500 RPM durante 10 minutos, posteriormente se extrajo el plasma y se volvió a centrifugar a 7000 RPM durante 10 minutos y se almacenaron a $-70^{\circ} \mathrm{C}$, luego las muestras se procesaron en un lapso no mayor a 6 horas posteriores a la toma. Se realizó un procesamiento estándar de digestión con proteinasa $\mathrm{K}$ (Bioline) para eliminar proteínas que se unen al ADN y que pueden afectar la q-PCR; para esto se utilizó una concentración de $5 \mu \mathrm{g} / \mathrm{mL}$ de proteinasa $\mathrm{K}$ en un buffer que contiene $50 \mathrm{mM}$ de Tris-HCL y $2 \mathrm{mM}$ de acetato de calcio, el cual se diluyó en $40 \mu \mathrm{L}$ de plasma, esta mezcla fue incubada toda la noche a $37^{\circ} \mathrm{C}$. Luego de esto, para evitar interferencias asociadas con procesos de separación adicionales, se amplificó el ADN directamente del plasma sanguíneo tratado con la proteinasa $\mathrm{K}$.

\section{Cuantificación de ADN en plasma}

Para la cuantificación de ADN libre presente en plasma se utilizó el protocolo establecido por Umetani y colaboradores $(17,18)$. La q-PCR se realizó con el kit de Sybr green (Applied Biosystem), amplificando la secuencia ALU 115 usando los primers:5 CCTGAGGTCAGGAGTTCGAG 


\section{3`y 5 'CCCGAGTAGCTGGGATTACA3`. La} cuantificación absoluta se llevó a cabo con el equipo de q-PCR ABI 7500 Real-Time PCR System, utilizando una curva estándar de concentración $\left(2.5^{*} 10^{-06}\right.$ a 2.5 ng) para cada reacción se calculó la concentración de ADN con los Ct (Ciclo Umbral) respectivos de cada paciente. Un control negativo (sin molde) fue usado en cada reacción. Se realizó la evaluación en gel de agarosa al $2 \%$ para confirmar el tamańo del producto. Los componentes y concentraciones de cada reacción de ALU - q-PCR fueron los siguientes: $12,5 \mu \mathrm{L}$ de Master Mix (Syber Green Applied Biosystem), 12,05 $\mu \mathrm{L}$ de agua, $50 \mathrm{mM}$ de primer forward y reverse y $0,2 \mu \mathrm{L}$ de molde.

\section{Análisis estadístico}

Los resultados se analizaron con el programa XLSTAS 2008. Al no cumplirse los supuestos de normalidad y homogeneidad de varianza se realizó estadística no paramétrica para determinar si existían diferencias de concentración de $\mathrm{ADN}$ entre mujeres y hombres y entre los diferentes rangos de edad establecidos, para la cual se definió como $\mathrm{P}<0,05$.

\section{Resultados}

\section{Tamaño de la muestra}

El cálculo de la muestra se hizo empleando un muestreo aleatorio simple a partir de la varianza obtenida de un premuestreo para los cuatro rangos de edad. Así, para cada rango de edad, se realizó un premuestreo de 20 individuos y el $\mathrm{n}$ poblacional resultante del análisis de varianza para cada rango fue el siguiente: Rango $1 \mathrm{n}=100$, Rango $2 \mathrm{n}=65$, Rango $3 \mathrm{n}=60$, y Rango $4 \mathrm{n}=61$.

\section{Número de muestras}

De las 340 muestras de las entidades participantes, 190 correspondieron a Dinámica IPS y 150 al Hospital de Engativá. En la Tabla 1, se resumen los datos recolectados. Se excluyeron el 7,3\% de las muestras porque no se observó especificidad en la curva de disociación o porque los valores obtenidos estaban fuera de los límites establecidos en la curva estándar.

\section{Curva estándar}

La curva estándar tuvo un coeficiente (r2) 0,982 y una eficiencia del 98\%, el límite máximo y mínimo de cuantificación de ADN en plasma fue $2,5 \mathrm{ng}$ y $0,001 \mathrm{pg} / \mu \mathrm{L}$ respectivamente, la linealidad se mantuvo desde el primer punto de la curva hasta el último, Figura 1.

\section{Concentración de ADN libre en plasma por PCR tiempo-real}

Las concentraciones de ADN libre en plasma por q-PCR con lo primers ALU fue 0,72861 \pm $1,28291591 \mathrm{ng} / \mu \mathrm{L}$ (Media y SD) para el total de las 340 muestras.

\section{Niveles de ADN libre en plasma en mujeres y hombres}

Se compararon los niveles de ADN libre en plasma en 160 muestras del género masculino y 180 muestras del género femenino. Para las mujeres se obtuvo una concentración promedio y desviación estándar de $0,46464745 \pm 1,14 \mathrm{ng} / \mu \mathrm{L}$ respectivamente y para los hombres 0,62225767 $\pm 1,75 \mathrm{ng} / \mu \mathrm{L}$, Figura 2 . Después del análisis estadístico no se encontraron diferencias significativas entre hombres y mujeres ( $\mathrm{P}>0,7)$ (Man-Whitney)(Kruskal-Wallis).

Tabla 1. Resumen de las características socio-demográficas más relevantes.

\begin{tabular}{llllllllllll}
\hline & \multicolumn{3}{c}{ Género } & \multicolumn{4}{c}{ Estrato } & \multicolumn{4}{c}{ Antecedentes Cáncer } \\
\cline { 2 - 5 } & Hombre & Mujer & 1 & 2 & 3 & 4 & 5 & 6 & Si & No. \\
$\mathrm{I}(<10$ años $)$ & 18 & 12 & 3 & 17 & 9 & 1 & - & - & 6 & 24 \\
$2(11-25)$ & 43 & 38 & 9 & 38 & 29 & 2 & 2 & 1 & 22 & 59 \\
$3(26-40)$ & 39 & 52 & 2 & 37 & 29 & 16 & 6 & 1 & 30 & 71 \\
$4(>41$ años $)$ & 43 & 90 & 9 & 42 & 40 & 15 & 14 & 13 & 30 & 113 \\
\hline
\end{tabular}


A.
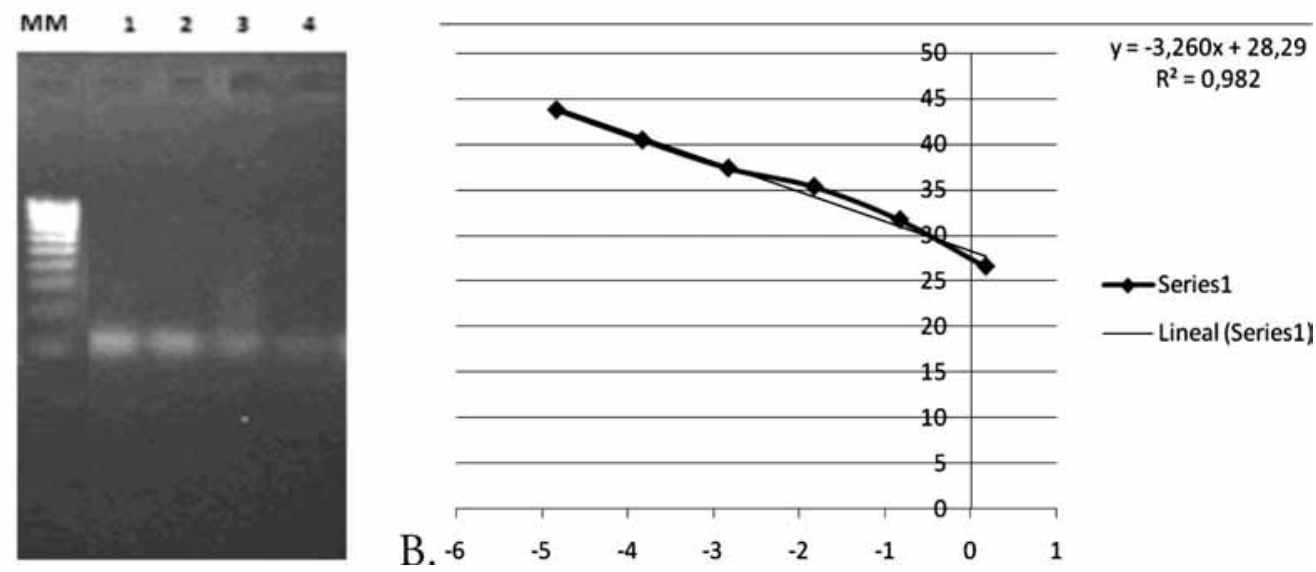

Figura 1. A) Electroforesis en gel de agarosa al $2 \%$ confirmando el tamaño del amplificado de la curva estándar en la q-PCR, MM: Marcador de peso, 1: dilución 1/10, 2: 1/100, 3: 1/1000, 4: 1/10000. B) Regresión lineal. En el eje X está el logaritmo de la concentración de cada dilución 2.5*10-06 a 2.5 ng y en el eje $\mathrm{Y}$ los $\mathrm{Ct}$ de los mismos.

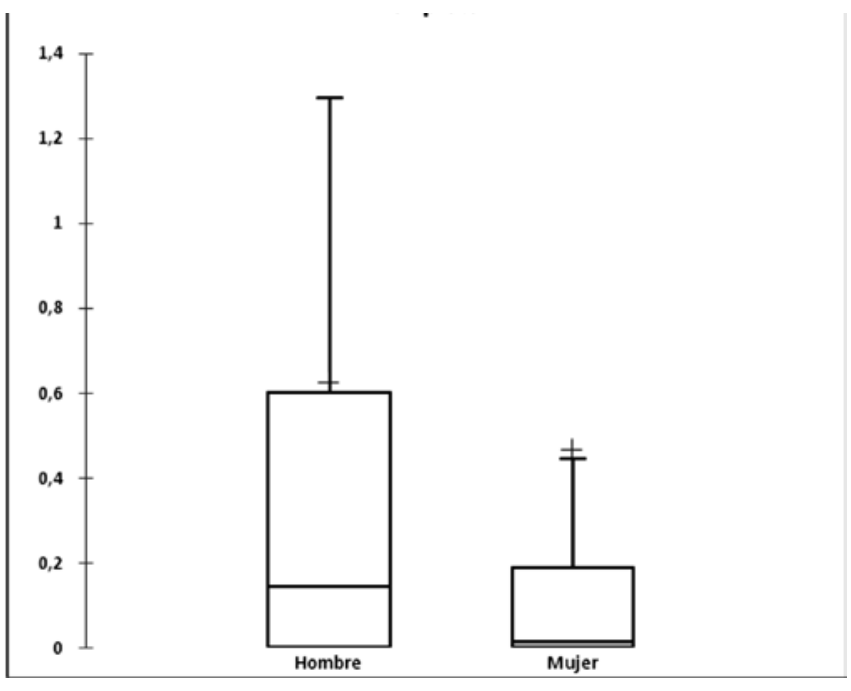

Figura 2. Concentración promedio y desviación estándar de ADN libre en plasma de 160 hombres y 180 mujeres.

\section{Niveles de ADN libre en plasma en diferentes rangos de edad}

De los 4 rangos de edad establecidos, se obtuvieron las siguientes concentraciones: los niños menores de 10 años tuvieron una concentración promedio de $0,86154482 \pm 1,22926684 \mathrm{ng} / \mu \mathrm{L}$, el rango de 11 a 26 ańos tuvo una media de $0,61047658 \pm$ $0,56593443 \mathrm{ng} / \mu \mathrm{L}$, las personas de 27 a 40 ańos tuvieron una media de $0,51797072 \pm 0,22067375$ $\mathrm{ng} / \mu \mathrm{L}$ y los adultos mayores de 41 ańos tuvieron una concentración media de 0,50118392 $\pm 0,25799191$ $\mathrm{ng} / \mu \mathrm{L}$, Figura 3 . No se observaron diferencias

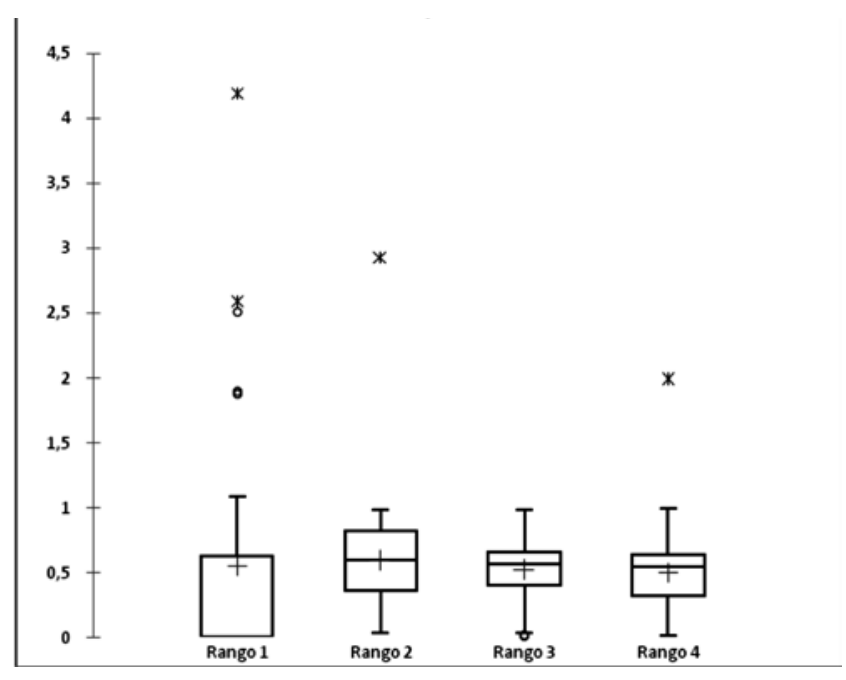

Figura 3. Concentración promedio y desviación estándar de ADN libre en plasma de los 4 rangos de edad.

significativas en la concentración de ADN libre en plasma entre los diferentes rangos de edad $(p>0,05)$ (Friedman).

Adicionalmente se analizaron las concentraciones de $\mathrm{ADN}$ libre en sangre entre los diferentes estratos y entre los individuos que presentaron antecedentes con cáncer y los que no, para esto se realizaron pruebas no paramétricas que se ajustaron a la distribución de los datos. No se encontraron diferencias significativas entre los diferentes estratos sociales, ni entre los individuos con antecedentes con cáncer y los que no tenían ( $\mathrm{p}>0,05)$ (Friedman)( Man-Whitney). Se 
compararon los niveles de $\mathrm{ADN}$ libre en plasma de ambos géneros en cada uno de los rangos y como resultado se obtuvo que en ninguno de los rangos hubo diferencia significativa ( $\mathrm{p}>0,05)$, Figura 4.

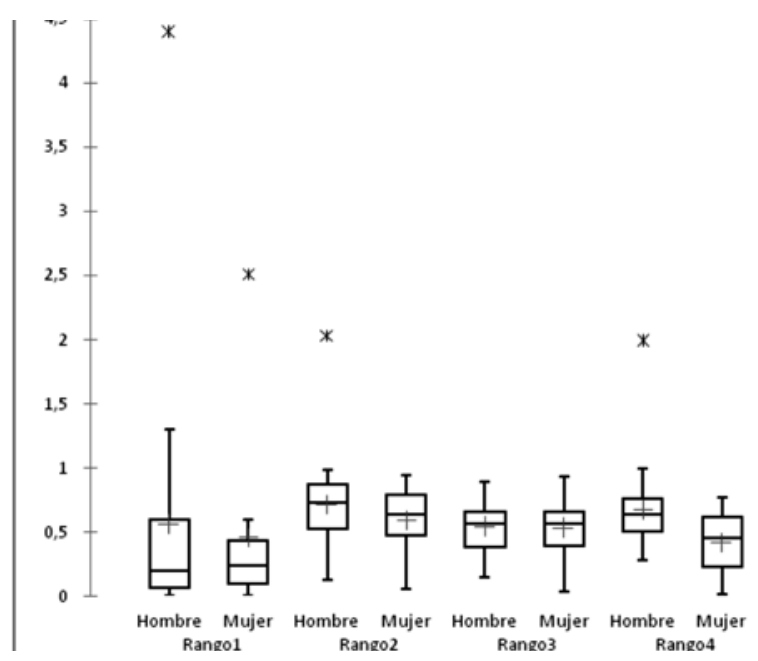

Figura 4. Concentración promedio y desviación estándar de ADN libre en plasma de hombres y mujeres de cada rango de edad.

\section{Discusión}

En este trabajo se determinó la concentración media de $\mathrm{ADN}$ libre en plasma de la población bogotana, con el fin de poder utilizarla como un valor de referencia para posteriores estudios en los que se deseé comparar los niveles de ADN libre en plasma respecto a diferentes enfermedades. Cabe resaltar que para dichas comparaciones es preciso seguir un mismo protocolo (método de separación del plasma, mismos primers, cuantificación directa desde el plasma evitando el método de extracción) para que sean comparables los niveles. Se pudo cuantificar el $\mathrm{ADN}$ libre en el plasma en voluntarios sanos al igual que lo han realizado varios autores $(1,14,15,17,18)$, esto se verificó con los resultados obtenidos mediante la q-PCR; se evidenció con la curva de disociación y con un gel de agarosa al $2 \%$ la banda o amplicon esperada de 115pb (ALU115).

En otros estudios, en donde han utilizado pequeños grupos de personas como controles, se han encontrado concentraciones medias de ADN libre en plasma de 0,0571 +/- 0,0306 ng/ $\mu \mathrm{L}$ (14); existen estudios que aceptan concentraciones de 0 hasta 35,2 ng/ $\mu \mathrm{L}$ (9); para otros autores, los valores normales son de 10 a $30 \mathrm{ng} / \mu \mathrm{L}$, con una media de $0,013 \mathrm{ng} / \mu \mathrm{L}$ (1) o de $0,018 \mathrm{ng} / \mu \mathrm{L}$ (15), mientras que en esta investigación se encontró una concentración promedio de $0,72 \mathrm{ng} / \mu \mathrm{L}$, la cual es superior a las anteriormente reportadas, esto se puede asociar a las diferentes técnicas utilizadas en las cuales se realiza extracción y purificación de $\mathrm{ADN}$ en donde puede haber una pérdida de ácidos nucléicos.

Además, las técnicas utilizadas en algunos casos no son precisas, por lo que en el estudio de Steinman y colaboradores, donde hay un valor muy elevado puede ser producto de la técnica (9). Por esta razón no es conveniente comparar los resultados obtenidos en este trabajo con los ya publicados por otros investigadores que realizan extracción y purificación de ADN. Sin embargo, Umetani y colaboradores $(17,18)$, cuantificaron ADN libre directamente del plasma y del suero, encontrando que para una muestra de 51 voluntarios sanos de California, Estados Unidos, la concentración media fue de 0.34 $\mathrm{ng} / \mu \mathrm{L}$, mientras que en la población bogotana se obtuvo una concentración promedio de $0,729 \mathrm{ng} / \mu \mathrm{L}$.

Estas diferencias se podrán asociar a las variabilidad genotípica que existen entre las diferentes poblaciones, en este caso Estados Unidos y Colombia, sin embargo, también podría tener influencias importantes en relación a aspectos de carácter nutricional y a las posibles diferencias existentes en el recambio celular que podrían ser mayores en Bogotá debido a la diferencia de alturas (California está al nivel del mar mientras Bogotá está a 2600 metros), no obstante es importante tener tamaños muestréales más representativos para poder comparar los valores.

Al observar las desviaciones estándar obtenidas en los cuatro diferentes rangos y en el total de los datos se pueden inferir los siguientes aspectos: en primer lugar, es importante resaltar que para la media global de 0,72 la desviación estándar de 1,28 es bastante grande ya que sobrepasa el valor de la media, este valor tan alto se debe a la existencia de varios valores extremos, sin embargo, al analizar las medias y desviaciones estándar de los 4 rangos de edad se observa que un solo rango es el que tiene la mayoría de valores 
extremos y una desviación estándar por encima del promedio, mientras que en los tres rangos restantes la desviación estándar es menor.

Al parecer los individuos menores de 10 años tienen un rango muy amplio de ADN libre en sangre, el cual se puede adjudicar a la toma de muestra que es mucho más difícil en niños que en adultos, por lo que el rompimiento de células sanguíneas en la toma de muestras puede aumentar notablemente la concentración de $\mathrm{ADN}$ libre (8). Adicionalmente, debido a la dificultad de conseguir muestras, este rango de edad fue el más pequeño especialmente por la falta de voluntad de los padres; por lo que un mayor número de individuos en este rango se hace necesario.

Respecto al origen del ADN libre, Lui y colaboradores en el 2002, estudiaron la contribución de las células hematopoyéticas al ADN libre en plasma, encontrando que estas células son una de las principales fuentes de ácidos nucléicos. Sabiendo que el número de los glóbulos rojos es mayor en hombres que en mujeres, en el presente trabajo se examinó si la concentración de $\mathrm{ADN}$ podría estar relacionada con el género (19), pero no se encontraron diferencias significativas. Tampoco se encontraron diferencias significativas entre los cuatro rangos de edad, lo que implica que las diferencias en glóbulos rojos y otras condiciones fisiológicas no afectan la liberación de ADN a la circulación, estos resultados concuerdan con los ya publicados por Zhong y colaboradores (8) quienes no encontraron diferencias entre los géneros y tan solo las mujeres mayores de 60 años mostraron una diferencia significativa del resto de los individuos. Los investigadores afirman que puede deberse al bajo tamaño de la muestra.

Finalmente, teniendo en cuenta el promedio y la desviación estándar, es posible afirmar que los valores de $\mathrm{ADN}$ libre en plasma de la población bogotana no sobrepasan $5 \mathrm{ng} / \mu \mathrm{L}$. Esta información servirá para futuros estudios en los que se desee estudiar la contribución de algunas enfermedades a la liberación de $\mathrm{ADN}$ al sistema circulatorio, así mismo es importante que los futuros investigadores sigan este mismo protocolo para evitar la pérdida de $\mathrm{ADN}$ en pasos como la extracción. La concentración de ADN libre en plasma no está asociado a la edad ni al género y se encuentra en una concentración menor a $5 \mathrm{ng} /$ $\mu \mathrm{L}$ en la población bogotana. La q-PCR aplicada directamente al plasma es una técnica altamente reproducible, además la eliminación de los pasos de purificación y extracción del $\mathrm{ADN}$ reduce los erros técnicos, reactivos y costos de laboratorio.

\section{Agradecimientos}

Agradecemos a la facultad de medicina de la Universidad de La Sabana por su apoyo financiero para la ejecución de este trabajo, a los departamentos de farmacia y de biotecnología y al laboratorio de equipos comunes de la Universidad Nacional de Colombia por sus instalaciones para la realización del presente estudio y, en especial, a todas las personas que aceptaron hacer parte de esta investigación.

\section{Referencias}

1. Giacona MB, Ruben GC, Iczkowski KA, Roos TB, Porter DM, Sorenson GD. Cell-Free DNA in human blood plasma: length measurements in patients with pancreatic cancer and healthy controls. Pancreas. 1998;17:89-97.

2. Jung M, Klotzek S, Lewandowski M, Fleischhacker M, Jung K. Changes in concentration of DNA in serum and plasma during storage of blood samples. Clin Chem. 2003;49:1028-1029.

3. Stemmer C, Beau-Faller M, Pencreac'h E, Guerin E, Schneider A, Jaqmin D, Quoix E, Gabú MP, Oudet P. Use of magnetic beads for plasma cell-free DNA extraction: toward automation of plasma DNA analysis for molecular diagnostics. Clin Chem. 2003;49:1953-1955.

4. Sozzi G, Conte D, Leon ME, Cirincione R, Roz L, Ratcliffe C, Roz L, Cirenei N, Bellomi M, Pelosi G, Pierotti MA, Pastorino U. Quantification of free circulating DNA as a diagnostic marker in lung cancer. J Clin Oncol. 2003;21:3902-3908.

5. Pathak AK, Bhutani M, Kumar S, Mohan A, Guleria R. Circulating cell-free DNA in plasma/serum of lung cancer patients as a potential screening and prognostic tool. Clin Chem. 2006;52:1833-1842.

6. Jahr S, Hentze H, Englisch S, Hardt D, Fackelmayer FO, Hesch RD, Knippers R. DNA fragments in the blood plasma of cancer patients: quantitations and evidence for their origin from apoptotic and necrotic cells. Cancer Res. 2001;61:1659-65.

7. Fatouros IG, Destouni A, Margonis K, Jamurtas AZ, Vrettou C, Kouretas D, Mastorakos G, Mitrakou A, Taxildaris K, Kanavakis E, Papassotiriou I. Cell-free plasma DNA as a novel marker of aseptic inflammation severity related to exercise overtraining. Clin Chem. 2006;52:1820-1824.

8. Zhong XY, Hahn S, Kiefer V, Holzgreve W. Is the quantity of circulatory cell-free DNA in human plasma and serum samples associated with gender, age and frequency of blood donations?. Ann Hematol. 2006;86:139-143.

9. Steinman CR. Free DNA in serum and plasma from normal adults. J Clin Invest. 1975;56:512-515.

10. Trejo-Becerril C, Oñate-Ocaña LF, Taja-Chayeb L, Vanoye-Carlo A, Cetina L, Dueñas-Gonzalez A. Serum nucleosomes during neoadjuvant chemotherapy in patients with cervical cancer. Predictive and prognostic significance. BMC Cancer. 2005;5:65.

11. Dong SM, Pai PI, Rha SH, Hildesheim A, Kurman RJ, Schwartz PE, Mortel R, McGowan L, Greenberg MD, Barnes WA, Sidransky D. Detection and quantitation of human Papillomavirus DNA in 
the plasma of patients with cervical carcinoma. Cancer Epidemiol Biomarkers Prev. 2002;11:3-6.

12. Pornthanakasem W, Shotelersuk K, Termrungruanglert W, Voravud N, Niruthisard S, Mutirangura A. Human papillomavirus DNA in plasma of patients with cervical. Cancer. BMC Cancer. 2001;1:2.

13. Rogachev VA, Likhacheva A, Vratskikh O, Mechetina LV, Sebeleva TE, Bogachev SS, Yakubov LA, Shurdov MA. Qualitative and quantitative characteristics of the extracellular DNA delivered to the nucleus of a living cell. Cancer Cell Int. 2006;6-23.

14. Wu TL, Zhang D, Chia JH, Tsao KC, Sun CF, Wu JT. Cell-free DNA: measurement in various carcinomas and establishment of normal reference range. Clin Chim Acta. 2002;321:77-87.

15. Sozzi G, Conte D, Mariano L, Lo Vullo S, Roz L, Lombardo C, Pierotti MA, Tavecchio L. Analysis of circulating tumor DNA in plasma at diagnosis and during follow-up f lung cancer patients. Cancer Res. 2001;61:4675-4678.
16. Anker P, Mulcahy H, Chen XQ, Stroun M. Detection of circulating tumor DNA in the blood (plasma/serum) of cancer patients. Cancer Metastasis Rev. 1999;18:65-73.

17. Umetani N, Hiramatsu S, Hoon DS. Higher amount of free circulating DNA in serum than in plasma is not mainly caused by contamined extraneus DNA during separation. Ann NY Acad Sci. 2006;1075:299-307.

18. Umetani N, Kim J, Hiramatsu S, Reber HA, Hines OJ, Bilchik AJ, Hoon DSB. Increased integrity of free circulating DNA in sera of patients with colorectal or periampullary cancer: Direct quantitative PCR for ALU repeats. Clin Chem. 2006;52:1062-1069.

19. Lui YY, Chik KW, Chiu RW, Ho CY, Lam CW, Lo YM. Predominant hematopoietic origin of cf-DNA in plasma and serum after gender-mismatched bone marrow transplantation. Clin Chem. 2002;48:421-427. 